\title{
EPILEPSIA ESSENCIAL E CISTICERCOSE CEREBRAL (*)
}

\author{
MARCELLO OSWALDO ALVARES CORREA \\ Monitor da cadeira de Parasitologia da Fac. de Med. da Un. de S. Paulo. \\ Interno da 2.a M. H.)
}

\section{OBSERVAÇAO}

Nome: A. J. C. - Idade: 26 anos - Est. civil: Solteiro - Nac. Brasileiro - Prof.: Lavrador - Proc.: Capital - 3. ${ }^{\circ}$ M. H.

História da moléstia atual: No dia 26 de Julho, pela manhã, ao lavar o rosto o paciente foi surpreendido por repuxões e tremores na boca, movimentos èstes violentos, bruscos e que se sucediam com rapidez. Observando-se ao espelho observou que em tais movimentos o lábio inferior se projetava para a esquerda enquanto a boca ficava retorcida; incomodado voltou ao leito passando bruscamente, assim como se jetivo ou objetive, assim como se iniciava. Nenhum outro fenômeno subjetivo ou objetivo se fez sentir por esta ocasião.

No mesmo dia, por duas vezes repetiram-se os tremores e repuxões iniciando-se repentinamente, sem que o paciente sentisse qualquer sensação estranha que prenunciasse a sua proximidade, e terminando-se também bruscamentc. Durante 20 dias continuaram os "acessos" (sic) que sobrevinham de prefe-

rência pela tardinha, após o jantar, continuando pela noite a dentro. viço, sentiu uma sensação exquisita, um "ar difera, quando ía largar o serao mesmo tempo que o sangue fervi um "ar diferente" como que perfumado água finamente dividida. Sentiu-se tomo si lhe polvilhassem 0 corpo com puxos na boca - como sempre proeminando imediatamente começaram os re: se acentuando procurou se deitar prominando para a esquerda -; as tonturas pernas se movimentavam, os bracos mal o tinha feito quando os braços e respiração foi se tornando difícil, on os ondo e as pernas esticando - a perdeu os sentidos.

Os companheiros que o socorreram afirmaram que não espumou pela pouca. nem mordeu a língua o que : aliás, o próprio doente observou; tão com a respiração estertorosa e rosto arroxeado desordenadamente os membros,

Quando voltou a si sentiu-se

moles e uma formidável vontade de fraco, com zoeira nos ouvidos, pernas morava, deitou-se e imediatamente teve normir. Chegando ao barracão onde meiro, como éste de curta duração avaliada em 10-15 minute igual ao priYoltando do ataque dormiu profundamente para $10-15$ minutos pelo paciente. ància de vómito e de fato vomitou grande para acordar, pela madrugada, cọm

e amarga no início, branca e azeda no fim.

+ vista do que voltou ao servico, Santa Casa onde não conseguiu se internar

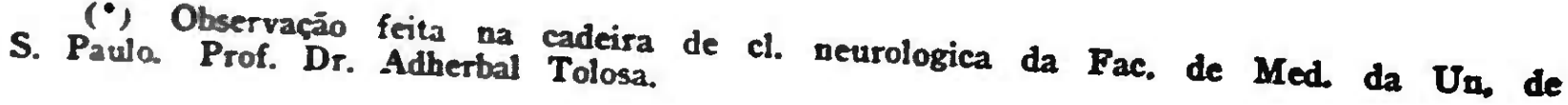


vez em quando, as mesmas sensações que precederam os ataques. Voltou a Santa Casa tendo então sido internado na $3 .^{\mathrm{a}} \mathrm{M}$. $\mathrm{H}$.

\section{INTERROGATÓRIO SOBBRE OS DIFERENTES APARELHOS}

Cabeça: desde os 10 anos de edade sofre regularmente de intensas cefaléas que sobrevêm repentinamente muito embora pressinta sua aproximação por uma sensação de “ar exquisito". E' de caráter martelante, pulsátil, sentindo a vista fraca embora não note manchas ou moscas volantes. Por estas ocasiões peoram os vômitos que relataremos adeante.

Olhos, Nariz, Ouvidos, Boca, Apar. Cárdio-respiratório: Nada digno de nota.

Ap. Gastro-intestinal: desde os 10 anos sofre de vez em quando de vômitos, sem relação com as refeições, sendo mais frequente com as cefaléas. Empachamento após as refeições.

Até ha cerca de 6 mezes, ou nas evacuações ou pela manhã na cama, tem expelido uns bichos semelhantes a semente de abóbora que se contraem ativamente como movimento de minhóca (sic.).

Sistema nervoso: Vide história.

Uro-genital: Nada digno de nota.

\section{ANTECEDENTES PESSOAIS E HÁBITOS}

Sempre trabalhou na roça, nos mais variados serviços. Refere, em particular que, quando creança, lidava no chiqueiro e se alimentava, bem como seus irmãos, de muita carne de porco.

Tem bom apetite. Alimentação pouco variada. Fuma cigarros de palha cerca de 20 por dia; bebe bastante café não sendo etilista.

Não se recorda de moléstia de infância. Pneumonia há 4 anos.

Há 2 anos, cerca de 15 dias após a copula apareceu-lhe na glande uma ferida de bordos regulares, com rebordo alto e duro da qual fez tratamerito 1ocal. Dois mezes depois apareceu-lhe no corpo todo, formações papulosas, de côr avermelhada, do tamanho duma moéda de $\$ 100$ que cederam com 5 injeções de 914. Não fez outro tratamento anti-luético.

\section{ANTECEDENTES FAMILIARES}

Pais falecidos de causa ignorada. De 3 filhos que eram, faleceu um irmão há 1 ano, com amarelão (sic), relatando que na véspera do desenlace, deitou grande quantidade de bichas parecidas a sementes de abóbora, contracteis, etc., isto é, eguais ás que o paciente tem expulsado. A irmã desde os 16 anos de edade que sofre de ataques eguais aos que teve o paciente e durante os quaes perde os sentidos, espuma pela boca, revira os olhos, bate os braços e pernas. Taes ataques sobrevêm em intervalos irregulares, ora semanas, ora de mezes. Não sabe informar como tem passado essa irmã ultimamente. Refere ainda que sabe de dois primos de 2.0 gráu que também sofrem de ataques semelhantes aos de sua irmã.

\section{EXAME FISICO GERAL}

Indivíduo leucodérmico, mediolíneo, aparentando a edade que relata, facies não característica, decúbito indiferente.

Péle quente, úmida, elástica, móvel sôbre os planos subjacentes; cicatrizes hipocrômicas com rebordo hiperpigmentado, esparsas pelo corpo com preferência pelo dorso. Pêlos com distribuição masculina. Panículo adiposo regular com predomínio no hipogastro. Não há circulação colateral.

Musculatura e arcabouço ósseos bem conctituidos. Mucosas vísiveis nornalmente coradas. Gânglios: palpáveis os cervicais, pequenos, duros e indolores e os inguino-crurais, do tamanho de uma caroço de azeitona, duros, móveis, indolores. Epitrocleanos não palpáveis.

Esternalgia e tibialgia ausentes. 


\section{EXAME FISICO ESPECIAL}

Cabisa: crànio - simétrico sem exostóses, nem pontos dolorosos.

Olhos: musculatura extrínseca normal. Pupilas isocóricas. Refléxos luminusus, consensual e de acomodação presentes e normais.

Orvidos, naris, scios da face: Nada digno de nota.

Boca: inúmeras fallas dentárias, algumas raizes infetadas, gengivite tartárica e piorréia. Lingua sem tremores nem desvios anormais.

Rebordo bucal simétrico com a boca aberta. Oro-faringe: nada digno de nota.

P'iscoşo: curto, cilindrico, sem estáse venosa e batimentos arteriais visíveis.

Tircoide palpável, não aumentada de volume. Não há Oliver-Cardarelli.

Aorta não palpável na fúrcula.

Tóra.r :

Aparellso respiratório: simétrico, com leve abaixamento do ombro direito: fossas supra e infra claviculares igualmente escavadas. Mamilos e omoplatas á mesma altura, igualmente afastados da linha mediana. Não há abaulamentos, nem retrações, nem tiragem.

Tipo respiratório costo-abdominal com a frequência de 18 movimentos p.m.

Litten visível dos 2 lados, em igual extensão.

Igual expansibilidade dos dois ápices: maior expansibilidade da base direita.

A palpação confirma êstes dados: frêmito tóraco - vocal de destribuição normal de acordo com o timbre da voz. $\AA$ percussão: som claro pulmonar em toda a área. Murmúrio vesicular normal.

Ap. cárdio-vascular: choque da ponta visível no $50^{\circ}$ E. I. E. 1 dedo para fóra da linha hemiclavicular; palpável, pouco intenso. Não se palpam frêmitos. Área cardíaca não aumentada. Bulhas com caractéres normais nos fúcos mitrais e tricúspide; desdobramento inconstante da $2 .^{a}$ pulmonar, clangor da 2. aórtica. Ártérias radiais elásticas, pulso cheio e tenso, batendo ritmiçamente com a frequência de 72 p.m.

P. A.: $125-80$.

Abdômen: Simétrico, com acúmulo de panículo adiposo na região infra umbelical; cicatriz umbelical com caractéres normais.

Não há resistências anormais, nem pontos dolorosos á palpação superficial. Transverso: palpável, largo, de consistência pastosa á esquerda onde é levemente doloroso. Céco: palpável, gargarejante, indolôr; ascendente palpável. Figado: bordo superior percutivel no $4 .^{\circ}$ E. I. D.; bordo inferior palpável a 1 dedo do rebordo costal, fino, indolôr. Não há dor á pressão no ponto cístico de Murphy. Baço: percutível ao nível da $8 .^{\mathrm{a}}$ costela na linha axilar média, palpável a 1 dedo do rebordo, na mesma linha, de consistência dura.

Ap. gênito-urinário: Nada digno de nota; não foi encontrada cicatriz alguma na pênis.

Sistema nervoso: (Vide o exame Neurológico).

\section{EXAME NEUROLÓGICO}

\section{a) Estado psíquico}

O paciente tem perfeita, orientação em relação a si próprio e ao meio ambiente: atento e com memória satisfatória. Inteligência regular com certa lentidão de associação ideativa. $E^{\prime}$ analfabeto, cultura sofrivel; não há desvios cla afetividade. Linguagem relativamente clara.

\section{b) Atitude}

Facies não característica. Não há perturbação do equilíbrio.

\section{c) Motricidade}

1.0) Molricidode voluntária: não há paralisias ou paresías. Força muscular um pouco maior á direita o que coincide com a dextria do paciente. 
Manobras de Barré, Mingazzini, Raimisti e do pé de cadáver: negativas.

Não há incoordenações motoras, quer de mecanismo cerebelar, quer de mecanismo sensitivo. Sinal de Romberg negativo.

$2^{\circ}$ ) Mobilidade passiva: tonicidade muscular normal á inspeção dos relevos, á palpação das massas musculares e aos movimentos articulares passivos que se processam em gráus e de modo normais.

$3^{\circ}{ }^{\circ}$ Motricidade automática: marcha sem caractéres anormais. Mímica expressiva, fala, deglutição, respiração e mastigação, sem distúrbios.

4. ${ }^{\circ}$ ) Motricidade involuntária:

a) Expontânea - ausente.

b) Reflexa - não há trepidações, nem clonus, nem sincinesias.

Reflexos clônicos superficiais: cutâneo-plantar, cremasterinos, superficial e profundo, cutâneo-abdominais, presentes e normais. Não há sinal de Babinsky nem suas variantes. Reflexos corneano presente'e normal.

Reflexos clônicos profundos: Aquilianos - presentes e normais.

Rotulianos - diminuidos aparentemente porquanto com a manobra de Jendrassicke tornaram-se normais.

Médio-pubiano: diminuição do componente crural. Os demais: presentes e normais, não havendo sinal de Mendel - Bechterew, nem de Rossolimo.

Reflexos tônicos: de postura - normais.

Reflexos vegetativos: reflexos pupilares fotomotor, consensual e de acomodação presentes e normais, não havendo Argyll-Robertson.

\section{d) Sensibilidade}

1) Subjetiva: alucinações olfativas e parestesias referidas na história.

2) Objetiva:

a) Superficial: sensibilidade tátil, térmica e dolorosa, presente e normais.

b) Profunda: barestésica batiestésica, palestésica, estereognóstica, visceral, presentes' e normais.

\section{e) Fenômenos tróficos e vaso-motores}

Não foram notados.

\section{EXAMES COMPLEMENTARES}

\section{Exame do líquido céfalo-raquidiano (10-9-40).}

Punção lombar em posição deitada.

$\mathrm{P}^{i} 13$ Pf. 14?

Stookey - normal.

Líquor límpido e incolor:

Citologia .................

Albumina $\ldots \ldots \ldots \ldots \ldots \ldots$

2,6 por mm. ${ }^{3}$

R. Pandy $\ldots \ldots \ldots \ldots \ldots \ldots$

0,20 grs. por litro

R. Benjoin .................

negativa

$R$. de Wassermann ...........

00000.00000 .00000 .0

R. Takata-Ara ............. negativa com $1 \mathrm{cc}$. negativa

2.0 Exame - (28-9-40).

Exame do líquido céfalo-raquidiano.

Pi 15

Líquor-límpido e incolor.

Citologia

24,8 por mm. ${ }^{3}$ linfo-monocitose. Não foram

Albumina $\quad \ldots \ldots \ldots \ldots \ldots \ldots$

R. Pandy $\ldots \ldots \ldots \ldots \ldots \ldots$ encontradas células eosinófilas.

0,20 grs. por lirto.

R. Benjoin $\ldots \ldots \ldots \ldots \ldots \ldots \ldots$.

opalescência.

R. de Wassermann ...........

00000.12210 .00000 .0

R. Takata-Ara .............

negativa

negativa com $1 \mathrm{cc}$.

$R$. de desvio de complemento para cisticercose - negativa. 
No siro mulmillio:

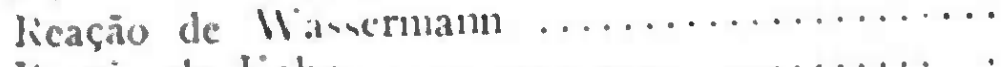

Kiesciun de haln .......................... fortemente positiva $(t+)$

fortcmente positiva $(t+)$

fortemente positiva $(t+)$

(a.) O. LANGE.

\section{RADIOGRAFIA DO CRÃNIO}

iiruis clinicis:

Tenia há 8 anos. Epilepsia parcial tipo facial.

Fianc Kudiolinico:

Projeção endo-craniana de duas inagens lípicas de cisticercose cerebral. $(10-9-4(1)$.

\section{EXAME HEMATOLOGICO}

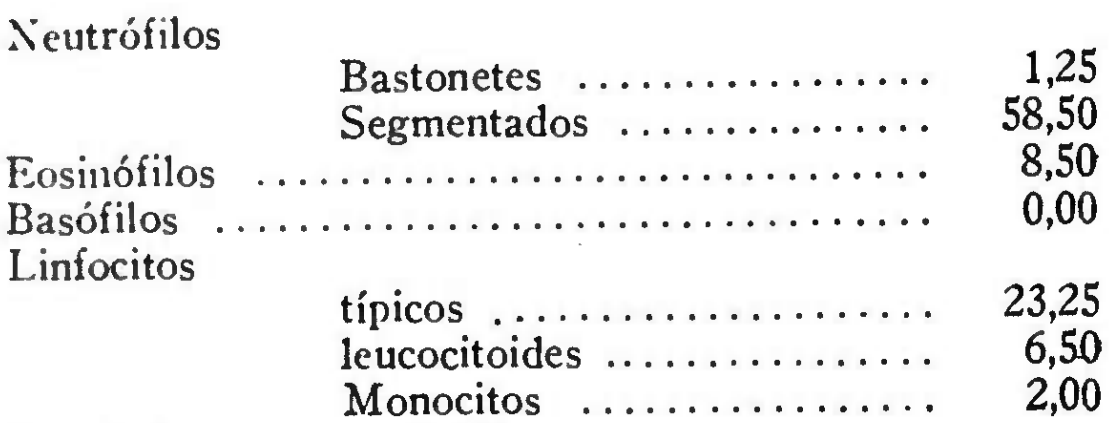

Granulações tóxicas nos neutrófilos

Frequentes linfocitos atípicos, com caractéres de imaturidade.

Eosinófilos com sinais de imaturidade.

$(1-10-40)$.

(a.) Michel A. Janra.

\section{DIAGNÓSTICO}

Dada a normalidade do exame clínico e neurológico, os elementos decisivos com que contamos para o diagnóstico, se limitam aos dados de anamnése e aos exames complementares.

Pela anamnése verificamos que a queixa principal do paciente consiste em manifestações iniciais de epilepsia tipo bravais-jacksoniana, em que o sinal - sintoma se traduzia por protundência do lábio inferior que se projetava para a esquerda; persistiram taes manifestaçues por 20 dias e então sobrevieram 2 ataques típicos de epilepsia generalizada, precedidas por aura-alucinações olfativas e parestésias - com perda dos sentidos, espuma pela boca, contrações clonicas, etc. \ão mais se repetiram tais manifestações, mas frequentemente o doente acusa a aura. isto é, as mesmas sensações olfativas e parestésicas que da vez primeira precederam os ataques.

Outros pontos merecem real destaque pelo seu possível significado de probabilidade diagnóstica. Desde criança costumava ingerir carne de porco, provavelmente sem grandes cuidados, daí a dilatada ofirortunidade de ingestão do cisticerco.

Com efeito esta sugestãr, se refrurcou porquanto é bem clara e significativa a informação de que costuma eliminar - e isto até há cerca de 6 meses - aneis ativos e contráteis, semelhantes a sementes de abóhora que evidentemente. são aneis de Taenis Saginata. Ora, esta taenia jamais acarreta a ladraria humana mas não exclue a pos- 
sibilidade, egualmente frequente e possivel, da existência concomitante da Taenia Solium, fonte causal duma possível contaminação auto-endógena.

Acresce que um de seus irmãos era grandemente parasitado, podendo funcionar como fonte de contaminação indireta do paciente.

Fator anamnéstico importante é relato de que uma irmã do paciente desde os 16 anos de idade, logo após a puberdade, portanto, sofre de ataques epilepticos generalizados - o grande ataque - dado. familiar que acresce de importância devido à informação de que dois. de seus primos também sofrem dos mesmos.

Devemos ainda lembrar que desde os 10 anos de idade sofre de cefaléas intensas, tipo enxaqueca, acompanhadas de vômitos; relata um nítido contágio sifilítico, há 2 anos, com manifestações cutâneas secundárias, tendo o tratamento anti-luético praticado se limitado a 5 injeções de 914. Dos exames de laboratório devemos realçar o desvio do complemento para cisticercose - fortemente positivo no sangue, negativo no líquor e as reações de Wassermann e Kahn - fortemente positivas apenas no sangue.

$$
* \quad * \quad *
$$

Resta-nos agora estabelecer qual a etiologia possível no caso para o síndrome epilepsia: si essencial, si por cisticercose cerebral ou si de origem luética. Nas considerações que se seguem passaremos em revista cada uma destas eventualidades, procurando enquadrar 0 presente caso numa das etiologias acima apontadas.

\section{CONSIDERAÇÕES GERAIS}

A epilepsia não é uma enfermidade de etiologia única. Em grande número de casos os ataques epilépticos constituem simplesmente a modalidade reativa do cérebro diante de lesões de diversas espécies : tal é a epilépsia sintomática. No entanto, tal denominação não significa que esta variedade de epilépsia a oponhamos como enfermidade orgânica do cérebro a uma epilépsia funcional, qualificada de idiopática, genuina ou essencial. Ao contrário, esta última deve ser considerada, com, razão, como uma afecção orgânica do cérebro, émbora seu subestrato anatámico seja desconhecido. $O$ número de epilepsias iidiopaticas propriamente ditas, reduz-se cada vez mais, á medida que aumentam os conhecimentos sôbre os múltiplos fatores que podem determinar as fórmas sintomáticas. Apesar de tudo, atualmente está perfeitamente justificada a classificação feita de ambas as formas. Admite-se a fórma idiopática máxime quando a anamnése resalta o caráter hereditário da afecção, ainda que êste dado possa oferecer grandes dificuldades em certas ocasiões, pois em algumas vezes, nos antecessores do paciente não houve grandes. ataques típicos ou, com frequência, só se obtem dados imprecisos, por exemplo, estados parecidos á enxaquecas. A epilepsia genuina póde depender de lesões germinais, especialmente nos filhos de al- 
coulatras e de sifiliticos, - mas sôbre esta questão reina ainda a obscuriclade, - já que é adimitido como possível uma lesão pré-natal, por exemplo, uma infecção sifilítica que seja o fator etiológico da epilepsia sintomática aparecida posteriormente. $\mathrm{Em}$ todos os casos nos quais se suspeita que houve lesões intra-uterinas, traumatismos obstréticos ou lesões cerebrais sofridas por crianças de mui tenra idade e scjam seguidos todos êles de ataques epilepticos na juventude, torna-se dificuldade considerável a de se decidir, si trata duma epilépsia genuina ou de uma forma sintomática.

Mais faceis são as circunstâncias quando os ataques epilepticos só aparecem, de modo evidente, como sintoma de lesões cerebrais conhecidas, como por exemplo, nos ataques, de ordinário agudos, transitórios e frequentemente únicos, consecutivos ás graves intoxicaçōes por álcool, cocaina, ópio, cânfora, óxido de carbono, assim como na eclanpsia, uremia, etc. Também aparecem ataques epiléticos na sífilis cerebral, paralisia geral, cistecercose, artério-esclerose cerebral, tumores cerebrais, encefalite, meningite, escleróse em placas, abcesso cerebral e em consequência de traumatismos cranianos. Nada de exato se sabe, todavia, com respeito ao caráter das lesões anatômicas que podem provocar a epilépsia sintomática. E' evidente que as irritações (quiçá á soma anormal das excitações) que determina os processos agudos ou crônicos, podem atual dessa maneira, mas não indefectivelmente. Supõe-se que essas irritações se desenrolam no cortex cerebral, sndo muito provável que tal fato ocorra nos ataques do tipo Jacksoniano, mas não está demonstrado para a forma genuina. Contudo, a aparição de ataques epilépticos nas afecções protoberanciais, faz crer que as zonas profundas encefálicas (suspeita-se do diencéfalo) deveriam entrar em consideração como ponto de origem dos ataques epilépticos. Assim mesmo, tem-se suposto que seriam de patogenia cortical as convulsões, enquanto que as contrações tônicas seriam produzidas pelas zonas corticais. Tais considerações não explicam sem dúvida, a causa íntima da tendência ás convulsões nem ao síndrome epileptico total. Ainda é muito incompleto o que sabemos a respeito das relações com anomalias metabólicas e transtornos endócrinicos, e sobretudo, com rspeito á questão global de uma possivel predisposição epiléptica.

\section{EPILEPSIA E CISTICERCOSE}

A etiopatogenia da cisticercose, já de muito está firmada e sabido é que o cisticerco patogênico para o homem vem a ser o C. celulose forma larvária da T. Solium, uma das "solitárias" muito comuns na infestação intestinal humana. Essa infestação cisticercósica sempre se faz por via digestiva, e, segundo a procedência dos embrionóforos ingericlos. deve ser dividida em dois grandes grupos:

$1 .^{\circ}$ - Da hétero-infestação, que vem a ser a ingestão de alimentos. contaminados pelos embrionóforos da tênia patogênica, de procedência externa. Isso acontece mais amiude nas zonas rurais, onde o consumo de frutas e de verdura é acudido pela própria pro- 
dução local em cuja cultura os adubos são generosamente utilizados, mesmo os de procedência humana. Além do mais, a falta de instalações higiênicas ocorre para larga disseminação dos excrétos portadores dos embrionóforos perigosos.

2. - Da auto-infestação, para a qual sempre é necessária a presença da tenia no intestino do próprio doente ( $T$. solium). Dá-se ela por via externa, nas crianças e nos dementes copófragos, na higiene individual precária; dá-se ainda por via interna, quando há digestão de um anel da tenia, levado acidentalmente (regurgitações, vômitos) ao estômago.

$O$ primeiro grupo, da hétero infestação explica bem as infestações pequenas ou mesmo únicas (principalmente oculares), enquanto que o segundo faz compreender as infestações maciças, totais: o doente fica como que crivado de cistecercos. A disseminação do parasita no organismo, uma vez vencida a parede intestinal em cujos vasos penetra, se faz por via sanguínea.

Quanto á frequência da localização da cisticercose no sistemia nervoso central, si não vai a 100\% também não distancia muito; uma das estatísticas mais numerosas é a de Vosgien que dos seus 807 casos encontrou 330 com localização do sistema nervoso, ou seja, $40,8 \%$.

Toledo Galvão, de 15 casos observados verificou 11 vezes a localização cerebral ou sêja, frequência de 73,3\%; Monteiro Sales afirma que a localização cerebral é a mais frequente na cisticercose humana e que a séde superficial é mais constante. Com efeito, de acôrdo com o citado autor estão as estatísticas de Coccioni e Pacheco e Silva, das quais se infére que na convexidade está a séde mais frequente da localização cerebral. $O$ cisticerco do sistema nervoso pode provocar toda sintomatologia cerebral possível uma vez que sua localização é viável em qualquer ponto onde chegue uma arteriola e que àos fenômenos locais por presença atual do cisticerco podem acrescer fenômenos outros acarretados pelas lesões á distância.

No que se refere, em particular, as manifestações epilepticas são condicionadas pela cisticercose das meninges, cortex e massa cerebral acarretando então, sintomas de tumor cerebral, com epilepsia tanto generalizada como do tipo bravais-jacksoniano. Monteiro Sales aponta como característico para epilepsia deste último tipo, a inconstância na localização no início dos ataques, isto é, na variabilidade do sinal sintoma. $\mathrm{O}$ citado autor em 15 casos encontrou 13 em que a epilepsia foi observada; Pacheco e Silva em 7 casos achou-a 5 vezes.

Para o diagnóstico da cisticercose devemos julgar com dados clínicos e com dados humorais.

1 - Dados clínicos: A) os comemorativos para a verificação das possibilidades de infestação pela tênia tanto no paciente como nos demais da família, possíveis fontes de contaminação pelos hábitos e modo de vida. 
B) A conconitância de cisticercos sbu-cutâneos exteriorisando-se por nódulos cuja natureza parasitária pode ser revelada por biópsia; sua raridade, no entanto, é extrema.

C) 1 presença comprovada da infestação intestinal por Tenia soliun o que condiciona as possibilidades de auto infestação interna e externa.

A comprovação exclusiva da Tênia saginata, cujos cisticercos não aparecem na infestação humana, nada indica de negativo porquanto não exclue a possibilidade duma concomitante infestação pela T. solium.

D) Deve ser sempre suspeitada nos quadros de hipertensão cerebral, nas epilépsias e no síndrome neurológicos polifocáis.

E) A radiografia do crânio confirmando um quadro de hipertensão já previsto ao exame clínico ou então fazendo diretamente o diagnóstico pela patenteação dos cisticercos calcificados.

O nosso caso apresenta dados de anamnése positivos já realçados, a suspeita pelo quadro de epilepsia e aparentemente, a positividade da radiografia. Dizemos "aparentemente" porquanto as chapas foram erroneamente interpretadas uma vez que nada há que possa ser claramente indicado como imagem de cisticerco; desta opinião foram os Profs. Tolosa e Gama.

2 - Dados humorais: A) Eosinofilia do sangue: de variações amplas, de valor meramente coadjuvante, não trazendo indica. ções valiosas porquanto é incontradiça em qualquer parasitóse.

B) Intradermo reação: praticamente sem valor porquanto além de ter muitas causas de êrro e dificuldade de leitura, é sobrepujada de muito por outros dados.

C) Sindrome liquórica: Relativamente rara, só aparecendo com caráter decisivo quando há extenso comprometimento das meninges: albumina entre 0,40 e 0,75 , globulinas positivas, reação importante eventualmente com eosinofilia, benjoim coloidal positivo nos 10 ou 12 primeiros tipos com curva do tipo meningo-sifilítico, reação de ouro-coloidal, e Wassermann negativo.

Nas formas cisticas que acarretam hipertensão, a punção nada mais faz que confirmar o diagnóstico de tumor cerebral.

D) Desvio do complemento no sangue e no liquor: no líquor a reação parece ser mais específica do que no sangue, isto é, mantemse negativa em ausência de cisticercose mas pode ser negativa em presença da mesma; daí a necessidade de fazer concomitamente a reação no sangue. E' possível pois, a existência da cisticercose cerebral com desvio do complemento no liquor e síndrome liquóricos negativos, com desvio do complemento positivo no sangue; tal seria o nosso caso e tal ocorreu no caso. n. ${ }^{\circ} 1$ da tese de Monteiro Sales em que a cisticercose foi comprovada. Ainda este autor, de estudos comparativos feitos em 84 casos, nos quais praticava o desvio do complemento para a cisticercose, e as reações de Wassermann e de Kahn, conclue pela não influência dos anticorpos sifilíticos sôbre os desvios do complemento. 
Aconselha ainda, M. Sales que, em caso de negatividade no líquor em presença de um caso dưvidoso, deve-se repetir a punção pois com intervalos de dias, o desvio do complemento pode-se tornar positivo.

O nosso caso apresenta eosinofilia sanguínea - 8,5\% - invalidada no entanto, pela positividade do ex. de fezes para ovos de Ancilostomideo, denunciando a existência do Necator ou do Ancilóstomo. Aliás esquecemos de transcrever o resultado dêste exame na parte competente.

A síndrome liquórica foi absolutamente negativa nas 2 punções bem como o desvio do complemento no líquor; foi positiva no sangue Em resumo, são dados positivos em favor de etiologia cisticercósica no nosso caso, os seguentes dados:

1) Dados de anamnése.

2) Reação do desvio do complemento positivo no sangue.

Com tais dados, não nos é possível afirmar desta etiologia como também não podemos afastá-la de todo, embóra haja mais possibilidade de que a cisticercose não intervenha neste caso.

\section{EPILEPSIA ESSENCIAL}

$E_{m}$ favor do diagnóstico de epilepsia essencial falam apenas os dados de coexistencia de casos analogos na familia do paciente; com efeito, o paciente tem uma irmã cujos ataques do tipo epilético generalizado se iniciaram aos 16 anos de idade.

Acresce que dois primos de $2^{\circ}$ gráo do paciente tambem sofrem de ataques que, segundo informações do mesmo são inteiramente analogos aos generalizadós de que foi acometido.

Segundo a opinião de outros autores que admitem a afinidade entre a enxaqueca e a epilepsia, contariamos com outro elemento de probabilidade pró diagnóstico de epilepsia essencial, porquanto o nosso paciente desde os 10 anos de idade sofre de crises de enxaquecas:

Com efeito, relata cefaléa intensas que sobrevêm repentinamente embora presinta sua aproximação por uma sensação de "ar esquisito". de caráter martelante, pulsatil, acusando enfraquecimento visual por estas ocasiões.

Sabido é que a epilepsia essencial predomina nos primeiros annos de vida e no periodo da puberdade, nos annos seguintes decrescendo a percentagem de incidencia. Ora, o nossio paciente tem a edade de 26 annos. o que não deixa de ser um elemento de pouca probabilidade para o diagnostico de epilepsia essencial, sem que no entanto o infirme, uma vez que não é de todo raro o aparecimento da mesma em tal edade.

$\mathrm{Na}$ anamnese do paciente pesquisámos, em vão, a ocorrencia dos ataques epilepticos atipicos, tambem chamados equivalentes, a menos que estabeleçamos uma correlação desta naturesa com a enxaqueca.

Concluindo, diremos que, embora não possamos afirmar pela epilepsia essencial, tambem não podemos excluil-a; fica assim o 
cliagnostico do nosiso caso oscilando entre a epilepsia sintomatica duma cisticercose cercbral e a epilepsia essencial.

Com isto deixamos de lado a etiologia luetica, uma vez que as reaçues especificas para a lues no liquor cefalo-raquidiano resultarem negatiras o que é dificil, senão impossivel, de conciliar com a existencia de processos lueticos assentados nas meninges cerebraes ou na propria massa encefalica. Acresce a negatividade do exame neurologico realisado, bem como do exame clinico geral.

Verdade é que na punção lombar, o liquor revelou linfo-monocitose o que, no entanto, não foi encontrado no exame do liquor anterior.

Afastada a etiologia luetica e restando pois a dupla probabilidade diagnostica de epilepsia por cisticercose cerebral e de epilepsia essencial. passamos a analisar o prognostico e a terapeutica destas duas eventualidades.

\section{PROGNOSTICO}

1) O prognostico da cisticercose, molestia de tratamento dificil e clelicado, sempre foi tido como sombrio, embora certos autores admitam mesmo a cura espontanea.

Monteiro Salles conclue que o prognostico quanto á vida é benigno na maioria das vezes, sendo mais sombrio quanto á função.

Naturalmente que o prognostico varia na rasão diréta da graviclade dos desarranjos nervosos, isto é, torna-se tanto mais sombrio - quanto á vida e á função - quanto mais grave fôr o quadro mórbido e quanto mais tardiamente fôr instituida a terapeutica.

2) $O$ prognostico da epilepsia essencial, quanto á função, é yrave porquanto se faz necessaria a limitação das atividades do doente; devem ser interditas todas as profissões arriscadas, em que haja perigo de quéda, deve ser prohibido o casamento, etc.

Quanto á vida, o prognostico varia de acordo com a gravidade do caso, porquanto desde as formas benignas - com crises isoladas, obedientes e curaveis á terapeutica - até as formas graves - com paroxismos convulsivos, repetição quasi diaria e resistentes á terapeutica - todas as formas intermediarias são possiveis.

Segundo Kraepelin, o prognostico é sempre sombrio porquanto a duração media da vida destes enfermos é claramente inferior ao normal, cerca da metade sucumbindo durante um acesso. A acumulação frequente dos ataques provoca o estado epileptico, durante o. qual sucumbem os enfermos por esgotamento, debilidade cardiaca ou sintomas de tumefação cerebral.

\section{TERAPEUTICA}

1) Terapeutica da cisticercóse: resumem-se em trez: operaçāo, radioterapia profunda e quimioterapia pelo extrato etéreo de féto macho. 
a) Operação: naturalmente a cirurgia será indicada quando se trata de cisticercos accessiveis, facilmente estirpaveis.

b) Radioterapia profunda: indicada nas sindromes de hidrocefalia por meningite serosa, podendo ser aliada ao tratamento cirurgico no pré-operatorio. E' de resultados duvidosos.

c) Quimioterapia: é o tratamento de escolha, consistindo no emprega de extrato etéreo de féto macho, na dose de 0,50 grs., diariamente, por series de 1 a 2 mezes consecutivos intervalados por. periodos de repouso. Pode e deve ser associado o tratamento sintomatico. Monteiro Salles relata 1 caso de cura e cita outros dois, tratados pelo Prof. Vampré, todos tratados com extrato etéreo de féto macho.

2) Terapeutica da epilepsia essencial: comprehende medidas de higiene, regimem e quimioterapia.

a) Higiene: em primeira plana o repouso fisico e moral, suprimindo as causas de excitação cerebral que produzem uma emoção violenta, uma fadiga excessiva, a sobrecarga intelectual, etc.

Deve ser preferida a vida do campo, evitado o álcool, etc.

b) Regimens E' claro que um epileptico deve evitar so repastos copiosos, os alimentos indigestos, o café forte, o tabaco em excesso; nestes ultimos annos, sob a influencia dos estudos humoraes na epilepsia. tem-se indicado varios regimens especiaes, dos quaes. releva em importancia o chamado regimen cetogenico.

Concebido pelos americanos, o regimen cetogenico procura obter a supressão das crises epilepticas realisando no doente um estado de acidóse com acetonuria. Para tanto, substituem-se quasi totalmente os hidrocarbonados pelas gorduras que realisando uma combustão incompleta acarretam a formação de acidos cetogenicos.

Este regimen é empregado exclusivamente em creanças e indicado quando os ataques se repetem com frequencia apesar do tratamento quimioterapico.

c) Quimioterapia: (1) Medicação bromurada: introduzida na epilepsia em 1851 por Locock, com resultados surprehendentes que nenhnma terapeutica tinha acarretado até então.

$\mathrm{O}$ 'bromo age sobretudo como um moderador das excitabilidades: reflexas dos rentros nervosos, ação esta tanto mais evidente quanto mais excitados estiverem estes centros.

Prescreve-se em doses variaveis conforme a edade do paciente e a gravidade da afeção; o bromureto de potassio é dado na dose diaria de 4 a 6 grs. e mesmo 10, para o adulto; 2 a 4 grs. na creança: de 12 a 15 annos. A duração pode ser indefinida, sendo melhor empregar doses crescentes e repouso por uma semana bem como associar a dieta desclorurada que permite redução da dose do bromureto.

(2) Fenil-etil-maloniluréa - luminal ou gardenal - é incontestavelmente o medicamento mais eficaz contra.a epilepsia; é um barbiturico da classe do veronal, com ação hipnotica e antiespasmodica. 
$O$ gardenal se prescreve na dose de 5 ou 10 centgrs. e de 1 centgr. filra creanças, doses cotas suficientes contra a insonia e angustia mas iusuficienter para a epilepsia.

Pole-se começar por 0,20 tomados 2 vezes por dia, fóra dos repastos.

Si a lose é insuficiente e a medicação bem suportada, aumenta-se diariamente 0.05 até obter bom resultados, podendo-se chegar até 0,40 .

Não ha risco de costume, devendo ser mantida a dose diaria suficiente, não se devendo suspendel-a bruscamente; quando as crises desaparcerem, reduzem-se as doses de 0,05 cada 2 mezes até se atingir 0,10 .

$\mathrm{Ha}$ vantagem en se associar a estrichnina que eleva a tolerancia para o gardenal; usa-se 0,0003 de sulfato de estrichnina para 0,05 de gardenal.

(3) Outros medicamentos: são usados barbituricos outros como rutonal, prominal e somnifeno, este ultimo sendo de indicação preçisa para suspender o estado de mal - uma ampola de $5 \mathrm{cc}$. intravenosamente.

São usados tambem a beladona, cloral, cloroformio, etc.

A beladona é usada na dose de 0,01 a $0,03 \mathrm{em}$ associação com o gardenal e a estrichnina.

Finalmente muitos autores recomendam o tratamento cirurgico, seja a secção do simpatico, de Jaboulay e Jonnesco, seja a simpatetomia peri-arterial de uma ou duas carotidas, de Lerische, seja a extirpação do glomerulo intercarotidiano, de Lauwers e Leriche.

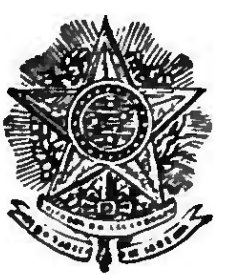

BRUNOZARATIN

16. TABELIÃO DE NOTAS

Rua Marconi, 100

Telefones

4-2880 4-2881

S. P A U L O 


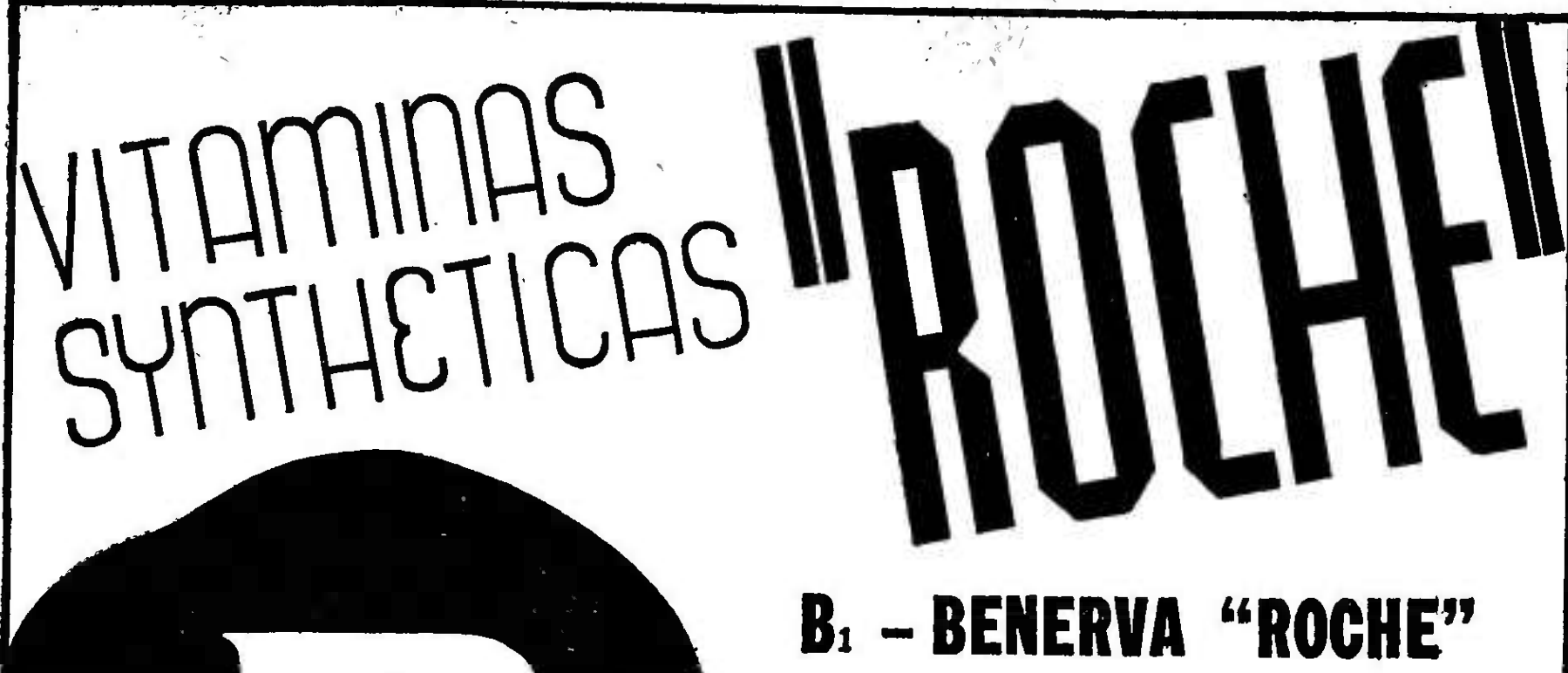

VITAMIDIA

Ampolas de $5 \mathrm{mg}$. (Caixa de 6)

Comprimidos de $3 \mathrm{mg}$. (Vidro de 20)

TODAS AS HIPOVITAMINOSES B1

NEVRALGIAS DIVERSAS
ASTHENIA.
DISTURBDOS INTESTINAES DORES MUSCULARES

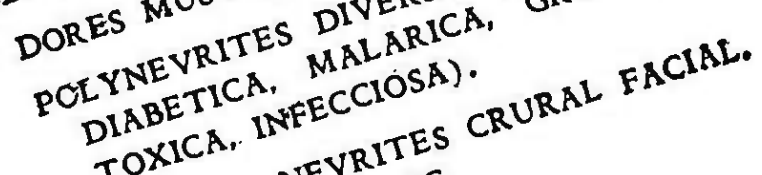
SCIATICA. NEVRITESC.

\section{BENERVA FORTE "ROCHE"}

PARA SUPPRIR, EM CASOS GRAVES, OS GRANDES DEFICITS EM VITAMINA B.

Ampolas de $25 \mathrm{mg}$. (Caixa de 3 )

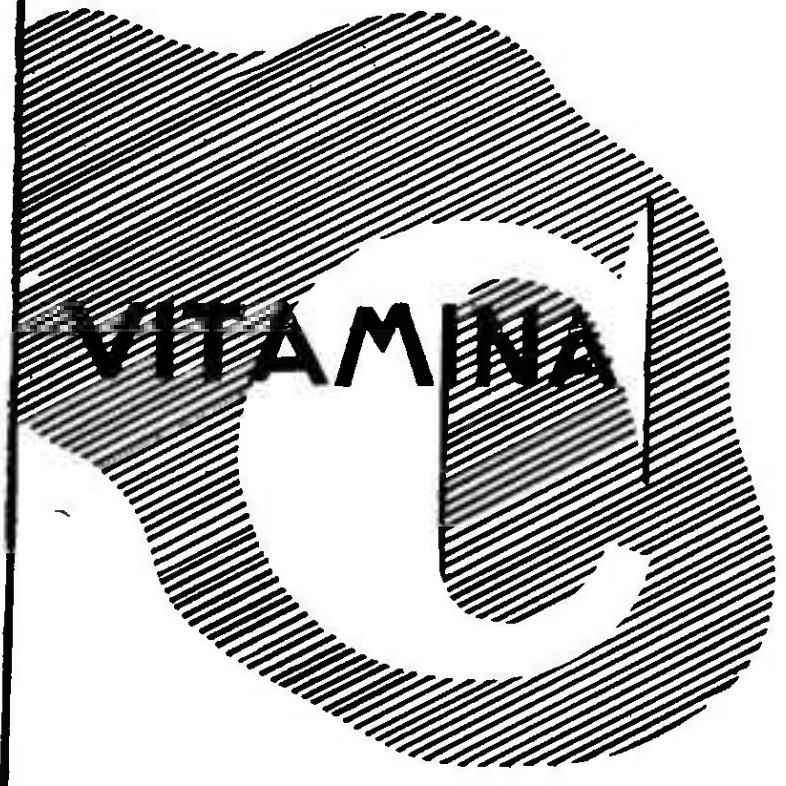

\section{C - REDOXON" "ROCHE"}

Ampolas dé $100 \mathrm{mg}$. (Caixa de 6)

Comprimidos de $50 \mathrm{mg}$. (Tubo de 20)

TODAS AS HYPO E AVITAMINOSES C. CARIE DEN-
HEMORR VICAS. DIATHESES GENGIVITE DY GTSOPHIA. PYOGENI. TARIA E COERCIVEIS. DYFECCOES PYLACTICO

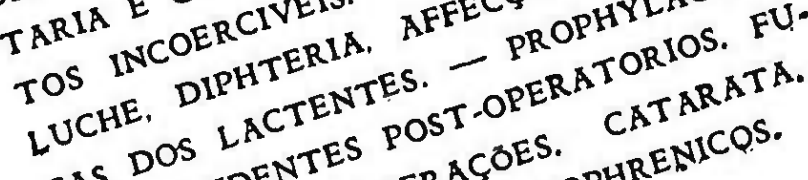
DOS ACCIDENTES ULCER ACSES. CATENICQS. RUNCULOSE. PRE E ESCHIZOP

\section{EST REDOXON FORTE} "ROCHE"

PARA SUPPRIR, NAS DOENCCAS INFECCIOSAS, OS GRANDES DEFICITS EM VITAMINA $C$ Ampolas de $500 \mathrm{mg}$. (Caixa de 3)

\section{PRODUCTOS ROCHE S. A.}




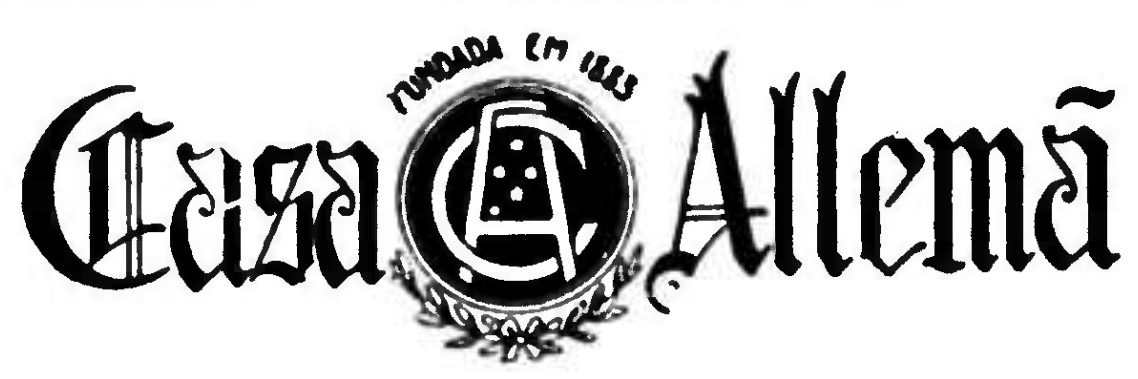

CAVALHEIROS! Nós offerecemos o maior sortimento de

Roupas para



CONFECÇÃO ESMERADA

A JUSTE PERFEITO

$N \tilde{A} O \quad E N C O L H E M$

\section{Preços vantajosos}

\section{TRAJES}

de lan e linho fantasia .......... $220 \$$ de linho puro branco ........... 245. de linho irlandez branco e perola ... 285\$ de linho irlandez, pardo ......... 295\$ de linho puro, perola ........... 320\$ de linho puro, fantasia ......... 330 de linho irlandez, typo S. 120 , branco $330 \$$ de linho irlandez, perola ......... 340\$ de linho irlandez, creme ......... 350\$ de linho irlandez, branco ........ 370 de Palm-Beach, côres ........... 395\$

TODOS ESTES TRAJES SÃO MOLHADOS NA NOSSA LAVANDERIA. Schaedlich, Obert \& Cia.

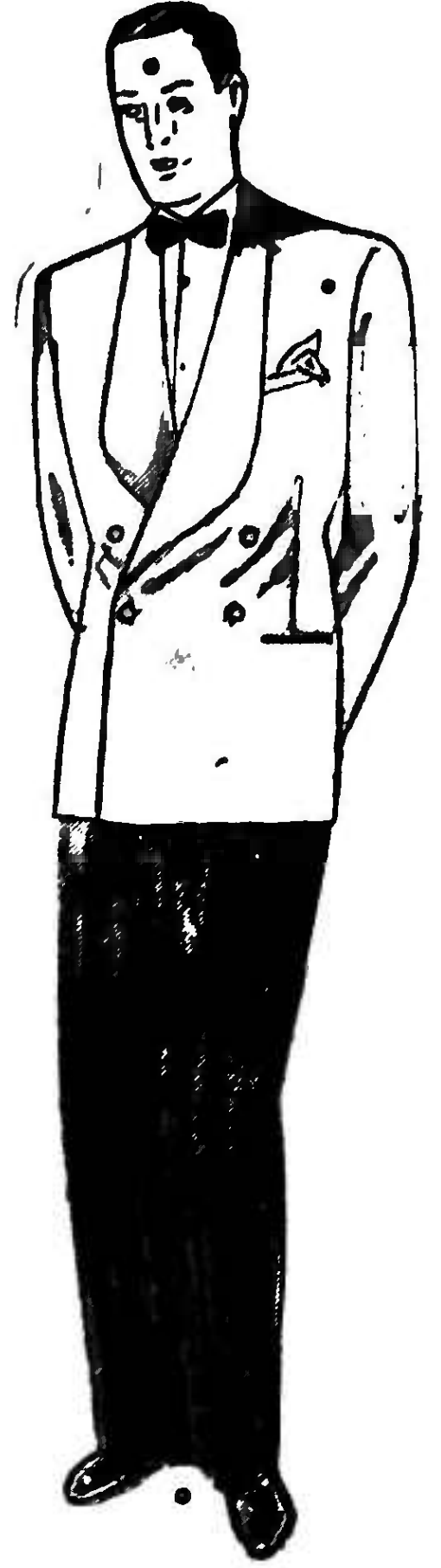

Summer - jacket 2806 Calça, lan preta 1308 Faixa 608 